\title{
BEMERKUNGEN ZUM FRÜHKAISERZEITLICHEN MÜNZVERKEHR DER UNGARISCHEN TIEFEBENE. REPUBLIKANISCHE UND FRÜHKAISERZEITLICHE MÜNZEN AUS DEM JÁSZSÁG (KOM. SZOLNOK/U)
}

\author{
PÉTER PROHÁSZKA
}

\author{
Archeologický ústav SAV v Nitre \\ 94921 Nitra, 2 Akademická, Slovakia \\ prohaszkapeter1975@gmail.com
}

\begin{abstract}
Although various works had been dealt with Roman money circulation of the Great Hungarian Plain some phenomena remained undiscovered for the research. This paper deals with republican and early imperial mints came to light in the territory of Szolnok County. The Jászdózsa hoard with its 114 pieces of Roman republican and early Roman period denars from P. Sulla (151 B.C.) to Emperor Nero (AD 64-68) belongs here. The Roman coins had appeared in large numbers only since the first century AD in the Great Hungarian Plain. The republican coins are very rarely represented, though they are very common in Transylvania. From the Zagyva mouth area to the river Tisza, and from the territory of the Jászság some hoards and scattering finds are known. It is difficult to interpret the circulation of these coins due to the lack of written sources and archaeological finds. Because of the Aurei the role of Roman politics should also be taken into consideration. Which gentes had lived in the territory of the Jászság and what role they had played in the relationship system of the Carpathian Basin we have rarely any information about. The hoard of Jászdózsa was probably hidden at about the Year of the Four Emperors (AD 69) or shortly thereafter.
\end{abstract}

Keywords: money circulation, Great Hungarian Plain, first century AD, coin hoards

Die römischen Münzen verschiedener Nominale und Prägeherren bilden einen bedeutenden und erheblichen Teil des römischen Fundmaterials im Barbaricum. Ihr Vorkommen und Rolle außerhalb der römischen Reichsgrenzen wirft manche Fragen auf, worauf die Forschung erst nach ihrer Sammlung, Bestimmung und Veröffentlichung eine Antwort zu geben vermag. Neben zahlreichen Streufunden kamen auch Münzhorte mit verschiedener Zusammensetzung zum Vorschein, welche wieder neue Fragen in Hinblick auf ihre Funktion und den Grund ihrer Verbergung aufwerfen. Aus dem mittleren Theißgebiet - so aus dem Gebiet des Komitates Szolnok - sind einige Münzhorte bekannt, die während der Mittleren Kaiserzeit verborgen wurden. Anhand ihrer Schlussmünzen kann man sie in eine chronologische Reihe setzen. 1. Der Hort von Tiszanagyrév: 62 Denare, Münzen von Nero bis Hadrianus, die Schlussmünze ist aus dem Jahr $133 \mathrm{n}$. Chr. ${ }^{1}$ 2. Tiszaföldvár-Ókincsemhegy: 60 Denare mit Münzen von Vespasianus bis Septimius Severus, die Schlussmünze wurde 193 n. Chr. geprägt. ${ }^{2}$ 3. Der Hort von Kunfehértó bestand aus 17 Antoniniani (von Gordianus III. bis Salonina) und wurde nach $268 \mathrm{n}$. Chr. verborgen. ${ }^{3}$ Neben den genannten kamen aber auch Münzhorte bzw. Streumünzen im Komitat zum Vorschein, die aus republikanischen und frühkaiserzeitlichen Exemplaren bestanden ( $A b b .1)$. Dieses Phänomen entging der Aufmerksamkeit der archäologischen bzw. numismatischen Forschung, obwohl das Komitat dank des Wirkens Andrea Vaday's zu den bestens erforschten Komitaten östlich der Donau hinsichtlich des römischen Fundmaterials gehört. ${ }^{4}$

${ }^{1}$ JÓNÁS $1926,38-39$
${ }^{2}$ HuSZÁr $1942,66$.

\footnotetext{
${ }^{3}$ PEKÁRY 1956, 50.

${ }^{4}$ S. zum Beispiel: VADAY 1989; VADAY 2005.
} 


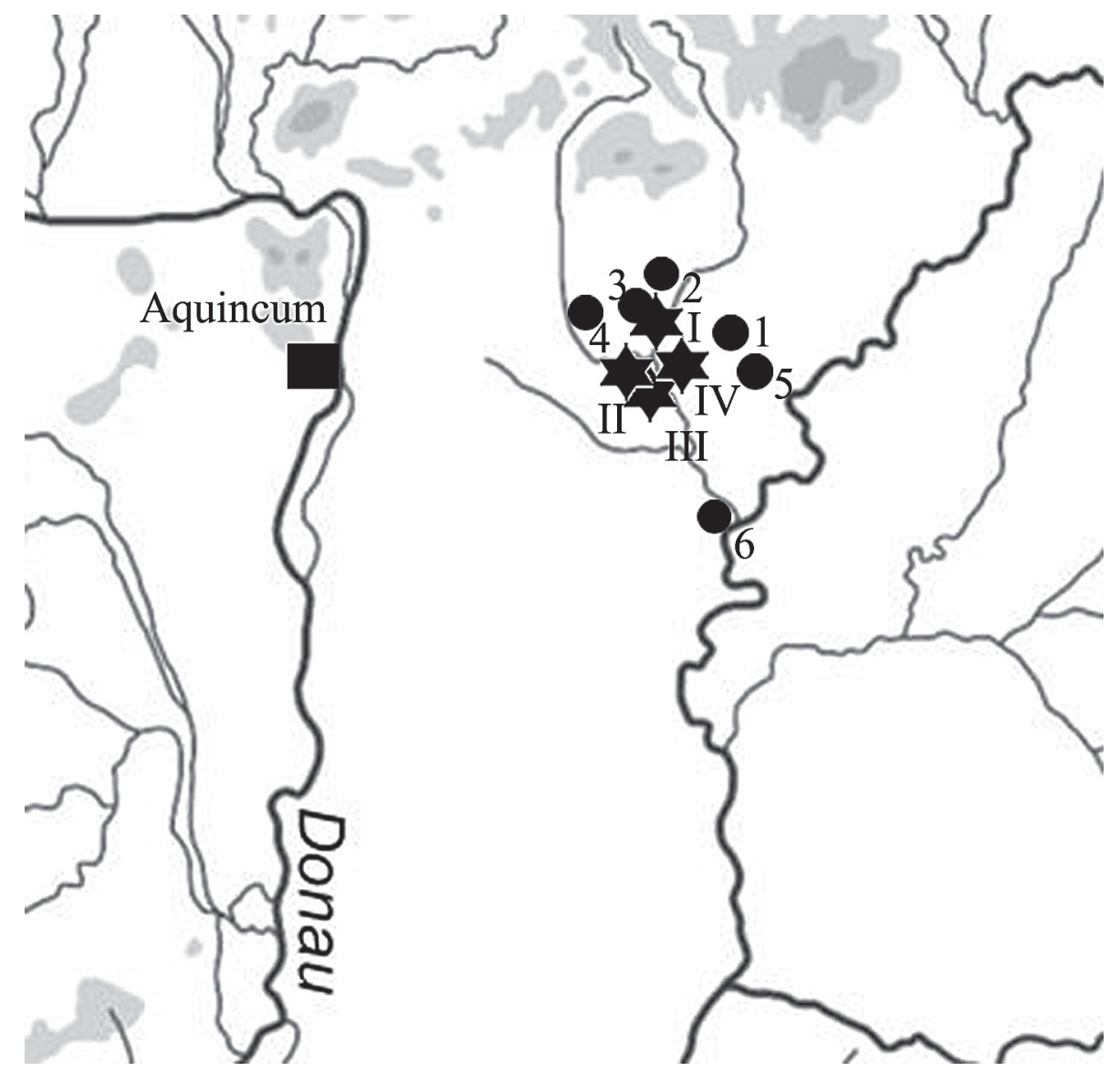

Abb. 1. Fundorte republikanischer und frühkaiserzeitlicher Münzen im Jászság. Münzhorte: I. Jászdózsa; II. Jászberény - Jakabi rész; III. Jászberény - Kerekudvar Gehöft; IV. Jászjákóhalma. Streufunde: 1. Jászapáti; 2. Jászárokszállás; 3. Jászdózsa; 4. Jászfényszaru; 5. Jászkisér; 6. Szolnok

Der größte kaiserzeitliche Münzhort des Komitats kam 1905 in Jászdózsa zum Vorschein und blieb bis vor einigen Jahren unbearbeitet. ${ }^{5}$ Die älteste Münze des Hortes ist ein Denar von P. Sulla (Craw 205/1 Rom [-151]) und seine Schlussmünze wurde zwischen 64 und 68 für Nero (RIC 53) in Rom geprägt. 90 \% des Hortes bilden republikanische Denare. Ihre Verteilung ist nicht gleichmäßig, weil die Münzen bestimmter Jahrzehnte fehlen. Die zwischen 150 und 70 v. Chr. geprägten Münzen sind im Großen und Ganzen kontinuierlich vertreten und machen $42 \%$ des Hortes aus. ${ }^{6}$ Danach gibt es Lücken in der Münzreihe, weil sich darin erst 4 Prägungen der 50er Jahre und dann 12 Münzen der 40er Jahre befanden. ${ }^{7}$ Von den in größter Zahl geprägten Bürgerkriegsmünzen kommen nur Legionardenare des Marcus Antonius vor, die aber $37 \%$ des Hortes ausmachen. Nach den hispanischen und lugdunumischen Prägungen des Augustus gibt es einen Hiatus bis zu den Denaren des Tiberius von 36/37 n. Chr. Die Schlussmünze des Hortes ist ein Denar des Nero. ${ }^{8}$

Die Bedeutung des Hortes ergibt sich gerade wegen der republikanischen und frühkaiserzeitlichen Münzen, weil oft darauf hingewiesen wurde, dass aus der Tiefebene kaum republikanische Denare bekannt sind. ${ }^{9}$ Hier beginnt der römische Münzverkehr erst mit den Prägungen der Flavier, aber erst ab dem Anfang des 2. Jahrhunderts kommen die römischen Münzen in größerer Zahl vor. ${ }^{10}$ Das Komitat Szolnok fällt im Vergleich auf, obwohl die bisherigen Analysen die Ähnlichkeiten des Münzverkehrs mit den anderen Gebieten der Tiefebene betonten. ${ }^{11}$ Ein Grund dafür war, dass das Münzmaterial nicht vollständig aufgenommen und bearbeitet wurde.

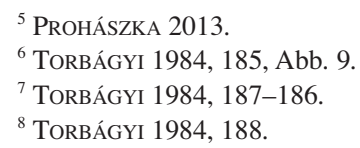

${ }^{9}$ GABLER 1975, 96; FÜLÖP 1976, 254-255.

${ }^{10}$ KÖHEGYI 1972, 104; GABLER 1975, 101; KÖHEGYI 1999.

11 VADAY 1970. 
Der Laienforscher Viktor Hild strebte seit Ende des 19. Jahrhunderts nach dem Erwerb der gefundenen archäologischen Objekte und der Münzen für seine Sammlung. Er war sehr gründlich und zeichnete auch die Fundumstände auf. ${ }^{12}$ Er erhielt sogar zahlreiche republikanische Münzen, die höchstwahrscheinlich aus gestörten Horten stammten. ${ }^{13}$ So bekam er im Dezember 1899 von einem Jászberényer Landwirt drei republikanische Denare, die in der Gemarkung von Jászberény beim Pflügen gefunden worden waren. ${ }^{14}$ Neben den zwei anonymen Denaren (Craw. 182/1 [-169-158] und 168/2 [-179-170]) war noch einer von Iullius Burrus (Craw. 352/1a Rom [-85]) dabei. ${ }^{15}$ Ebenfalls aus Jászberény stammen fünf republikanische Denare, die im Mai 1894 von János Szabó beim Pflügen im Gehöft Jászberény-Kerekudvar in einem Haufen gefunden worden sind. Es handelte sich um Prägungen des Q. Pilipus (Craw. 259 Rom [-129]), T. Manl. Q. Vr. (Craw. 299/1b Rom [-111/110]), M. Carbo (Craw. 276 Rom [-122]), L. Senti C. f. (Craw. 325 Rom [-101]) und Mn. Aquil Mn. F. (Craw. 401/1 Rom [-71]). Sie stammten höchstwahrscheinlich aus einem Hort. ${ }^{16}$ Ebenfalls zu einem Hort gehörten die vier Denare aus Jászjákóhalom, die Hild erhielt. Diese kamen im Herbst 1897 in der Gemarkung des Ortes zum Vorschein. Leider beschrieb Hild nur einen der vier Denare: M. Fovri L. F. Phili (Craw. 281/1 Rom [-119]). ${ }^{17}$ Hild erwarb auch einen Streufund für seine Sammlung. Der Denar wurde im Herbst 1894 beim Graben neben dem Kirchenturm in Jászárokszállás gefunden. ${ }^{18}$ Die Münze ist eine Prägung des P. Fourius Crusipa (Craw. 356/1a Rom [-84]). Die Reihe dieser Münzen können wir mit einem Denar des Victoriatus ergänzen, der aus Szolnok ins Ungarische Nationalmuseum gelangte, wo er als Babelon I 41, 8 (Craw. 44/1 Rom [-211]) bestimmt wurde. ${ }^{19}$ Neben den republikanischen Denaren gelangten einige frühkaiserzeitliche Münzen in die Sammlung von Hild, so ein Sesterz des Agrippa und einer des Tiberius, beide in Jászapáti gefunden. ${ }^{20}$

Sehr wichtig ist jener Aureus des Claudius (RIC 36 Rom [46/47]), der im Herbst 1892 in der Gemarkung von Jászfényszaru zum Vorschein kam. ${ }^{21}$ Ebenfalls aus Jászfényszaru ist ein As des Claudius bekannt. ${ }^{22} \mathrm{Zu}$ diesen gehören noch einige Münzen aus dem Jászság, die als Geschenk oder durch Kauf in das Ungarische Nationalmuseum gelangten. Zum Beispiel ein Aureus des Nero aus Jászkisér, ${ }^{23}$ worüber die Meinung des Museums erbeten wurde, ${ }^{24}$ oder der Aureus des Tiberius (RIC 25 Rom [14-37]), der in Jászdózsa zum Vorschein kam und durch Kauf ins Museum gelangte. ${ }^{25}$ Diese Goldmünzen sind bisher einzigartig im Münzverkehr östlich der Donau, weil die Zufuhr der Aurei im Barbaricum erst unter Nero begann. Die Aurei des Nero kommen aber überwiegend in der Südwestslowakei und im von Dakern bewohnten Siebenbürgen vor. Das Vorkommen der republikanischen Denare gehört auch zu diesen Phänomenen, weil sie überwiegend für die dakischen Gebiete, östlich der Theiß und in Siebenbürgen, kennzeichnend sind. ${ }^{26}$ Sie kommen auch in der Slowakei, vor allem im mittleren und oberen Waagtal, sowie zwischen den Flüssen Eipel und Gran, aber in geringer Zahl, vor. ${ }^{27}$ Drei kleinere Münzhorte sind dort bekannt: Zwei kamen am Waag (Rajecká Lesná) und einer am Sajó (Vráble) zum Vorschein. ${ }^{28}$

Republikanische Denare kommen noch im nordöstlichen Teil Transdanubiens vor, wo das Siedlungsgebiet der Eravisker lag. Hier erscheinen sie in der zweiten Hälfte des 1. Jahrhunderts v. Chr. ${ }^{29}$ Die republikanischen Denare konnten einerseits aus Transdanubien von den Eraviskern und den Römern oder aus den dakischen Gebieten nach Jászság gelangen. Es ist fraglich, ob die Ungarische Tiefebene im 1. Jahrhundert n. Chr. zum Dakischen Königreich gehörte bzw. von Dakern besetzt war. ${ }^{30}$ Den Kontakt zu den Eraviskern würde ein Denar eraviskischer Prägung aus dem Gebiet Szolnok untermauern, während derartige Prägungen im Jászság bisher nicht zum Vorschein kamen. ${ }^{31}$ Eine andere Möglichkeit wäre, dass diese Münzen gerade hinsichtlich der Aurei als Zeugen der römischen
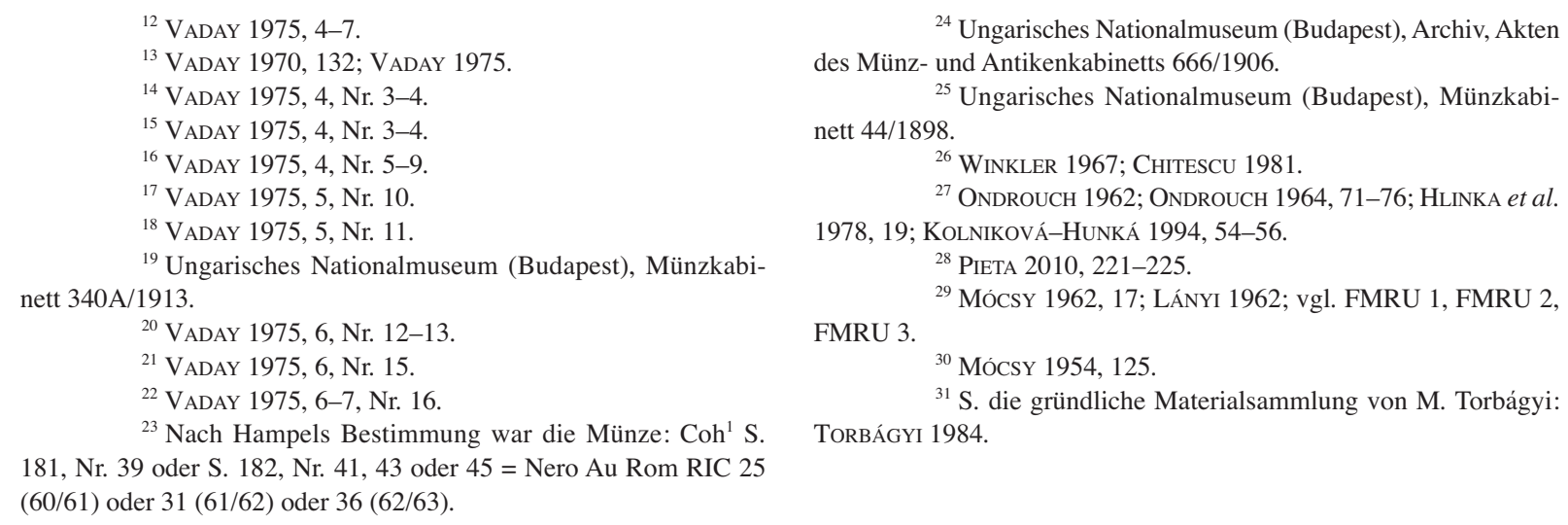
Außenpolitik betrachtet werden. Das Reich wollte die hier lebende Bevölkerung mit Subsidienzahlungen für seine Ziele gewinnen. Um wen es sich dabei konkret handelte, kann man mangels archäologischer Funde nicht bestimmen. Tacitus berichtet in Germania darüber, dass die unmittelbaren Nachbarn der Jazygen die keltischen Völker der Osi und Cotini waren. ${ }^{32} \mathrm{Ihr}$ Siedlungsgebiet wird aber in der heutigen Slowakei gesehen und sie werden mit der Púchov-Kultur in Verbindung gebracht. Auch die Möglichkeit wurde aufgeworfen, dass das Volk der Osi gegenüber Aquincum angesiedelt war. ${ }^{33}$ Die Münzen könnten auch durch Handel in Jászság gelangen, weil die Handelswege durch dieses Gebiet nach Osten und Norden führten. Eine andere Möglichkeit wäre, dass sie als Zahlungen bzw. Steuer den hier angesiedelten Sarmaten bezahlt wurden. ${ }^{34}$ Mangels sarmatischer Oberschichtgräber bzw. Funde müssen wir diese Vorstellung jedoch in Frage stellen. ${ }^{35}$ Die relativ hohe Zahl der republikanischen und frühkaiserzeitlichen Münzen deutet gegenüber den anderen Gebieten der Ungarischen Tiefebene darauf hin, dass die hier angesiedelte Bevölkerung eine wichtige Rolle in dieser Epoche spielte. Wie schon dargelegt, können wir mangels archäologischer Funde nicht entscheiden, wer diese Münzen erhielt. Das Erscheinen der Aurei ist in dieser Epoche vollkommen ungewöhnlich und zeigt, dass das hier angesiedelte Volk enge Kontakte zum Römischen Reich pflegen sollte, weil vor den Prägungen Neros kaum Aurei aus dem Barbaricum des Karpatenbeckens bekannt sind.

Die feinchronologische Analyse des sarmatischen und keltischen Fundmaterials dieses Gebietes können wir anhand der zur Verfügung stehenden wenigen Funde nicht verrichten. Obwohl Tacitus über das Erscheinen und die Rolle der Sarmaten in den germanischen innenpolitischen Kämpfen nördlich der Donau im Jahr 50 berichtet, ${ }^{36}$ werden das Gebiet, die Zeit und der Verlauf ihrer Ansiedlung im Karpatenbecken noch immer kontrovers diskutiert. Zwar erscheint das enge Kontakte mit dem Pontusgebiet zeigende frühsarmatische Fundmaterial in mittlerem Theißgebiet (Cegléd, Tiszaörvény, Pusztamonostor), aber die Datierung der Funde streut ziemlich breit. ${ }^{37}$ Der Schatz von Jászdózsa wurde seiner Schlussmünze zufolge um 64-68 n. Chr. oder direkt danach verborgen. Dahinter könnten ursächlich die im Barbaricum erfolgten Veränderungen nach den Ereignissen des Vierkaiserjahres stehen. So wurden der Schatz von Jászdózsa und die anderen Münzen von Mitgliedern eines Volkes versteckt, die entweder im Vierkaiserjahr auf der falschen Seite standen oder wegen des Vormarsches der Sarmaten nach Norden gezwungen waren, ihre früheren Siedlungsgebiete zu verlassen.

\section{KATALOG}

Jászapáti (Kom. Szolnok, Ungarn) (Abb 1.1)

Mit anderen Funden gelangten die Münzen in die Sammlung von Viktor Hild.

Münze: $1 \times$ Agrippa S, $1 \times$ Tiberius S.

Literatur: VADAY 1975, 6, Nr. 12-13.

Jászárokszállás - Kirchenturm (Kom. Szolnok, Ungarn) (Abb 1.2)

Im Herbst 1894 wurde eine republikanische Silbermünze neben dem Kirchenturm beim Graben gefunden.

Münze: $1 \times$ Craw. 356/1a Rom (-84).

Literatur: VADAY 1975, 5, Nr. 11.

Jászberény - Jakabi rész (Kom. Szolnok, Ungarn) (Abb 1.II)

1899 erhielt Viktor Hild drei republikanische Denare von einem Bauer, der die Münzen in der Gemarkung von Jászberény beim Pflügen fand.

Münzen: $1 \times$ Craw. 182/1 Rom (-169-158), $1 \times$ Craw. 168/2 Rom (-179-170), $1 \times$ Craw. 352/1a Rom (-85).

Literatur: VADAY 1975, 4, Nr. 3-4.

Jászberény - Kerekudvar Gehöft (Kom. Szolnok, Ungarn) (Abb 1.III)

János Szabó fand fünf Denare beim Pflügen im Kerekudvar Gehöft im Mai 1894. Die Münzen gelangten in die Sammlung von Hild.

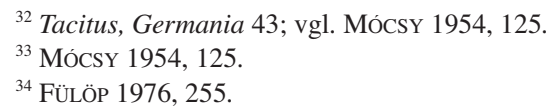

${ }^{35}$ KÖHEGYI 1984.

${ }^{36}$ Tacitus, Ann. XII, 29, 3; Mócsy 1954, 124.

${ }^{37}$ Mócsy 1954; KöHegYi 1984, 270-303, 344-345. 
Münzen: $1 \times$ Craw. 259 Rom (-129), $1 \times$ Craw. 299/1b Rom (-111/110), $1 \times$ Craw. 276 Rom $(-122), 1 \times$ Craw. 325 Rom $(-101)$, $1 \times$ Craw. 401/1 Rom (-71).

Literatur: VADAY 1975, 4, Nr. 5-9.

Jászdózsa (Kom. Szolnok, Ungarn) (Abb 1.1)

1905 kam ein Münzschatz aus 114 Denaren in Jászdózsa zum Vorschein, dessen Münzen ins Ungarische Nationalmuseum eingesendet wurden. Der Schatz bestand aus republikanischen und frühkaiserzeitlichen Denaren. Das Museum behielt nur einen Teil der Münzen, die anderen wurden zurückgeschickt. Die Bearbeitung erfolgte nach einer Liste mit Bestimmungen nach Babelon und Cohen.

Münzen: $1 \times$ D Craw. 205/1 Rom (-151), $1 \times$ D Craw. 208 Rom (-149), $1 \times$ D Craw. 220 Rom (-145), $1 \times$ D Craw. 223 Rom $(-142)$, $1 \times$ D Craw. 235/1 Rom (-137), $1 \times$ D Craw. 236/1 Rom (-137), $1 \times$ D Craw. 270 Rom (-125), $1 \times$ D Craw. 273/1 Rom $(-124), 1 \times$ D Craw. 281 Rom (-119), $1 \times$ D Craw. 283 Rom (-117/118), $1 \times$ D Craw. 286 Rom (-116/115), $2 \times$ D Craw. 289/1 Rom (-114/115), $2 \times$ D Craw. 299 Rom (-111/110), $2 \times$ D Craw. 300 Rom (-109/110), $1 \times$ D Craw. 308/1 Rom (-107/108), $1 \times$ D Craw. 312/1 Rom (-106), $1 \times$ D Craw. 316/1 Rom (-105), $2 \times$ D Craw. 324 Rom (-101), $1 \times$ D Craw. 337 Rom (-91), $1 \times$ D Craw. 341 Rom (-90), $1 \times$ D Craw. 343/1 Rom (-89), $1 \times$ D Craw. 345/1 Rom (-88), $3 \times$ D Craw. 348 Rom (-87), $1 \times$ D Craw. 352/1 Rom (-85), $1 \times$ D Craw. 353 Rom (-85), $1 \times$ D Craw. 361 Rom (-82), $2 \times$ D Craw. 362 Rom $(-82), 1 \times$ D Craw. 383 Rom (-79), $1 \times$ D Craw. 387 Rom (-77), $1 \times$ D Craw. 396/1 Rom (-74), $1 \times$ D Craw. 405 Rom (-69), $1 \times$ D Craw. 421 Rom $(-59), 1 \times$ D Craw. 425 Rom (-56), $1 \times$ D Craw. 427 Rom (-56), $1 \times$ D Craw. 428 Rom (-55), $1 \times$ D Craw. 430/1 Rom ( -55$), 1 \times$ D Craw. 448 Rom ( -48$), 2 \times$ D Craw. 463 Rom (-46), $2 \times$ D Craw. 463 Rom (-46), $1 \times$ D Craw. 463 Rom ( -46$), 1 \times$ D Craw. 464 Rom $(-46), 1 \times$ D Craw. 468 Hispanien (-45/46), $1 \times$ D Craw. 494/29 Rom (-42), $1 \times$ D Craw. 494/43 Rom (-42), $1 \times$ D Craw. 511 Sizilien $(-151), 1 \times$ D Craw. 518 Rom $(-41), 4 \times$ D Craw. 544/13 (-31/32), $2 \times$ D Craw. 544/14 (-31/32), $1 \times$ D Craw. 544/16 (-31/32), $1 \times$ D Craw. 544/18 (-31/32), $1 \times$ D Craw. 544/19 ( $(-31 / 32)$, $5 \times$ D Craw. 544/20 (-31/32), $2 \times$ D Craw. 544/21 (-31/32), $1 \times$ D Craw. 544/26 (-31/32), $1 \times$ D Craw. 544/27 (-31/32), $4 \times$ D Craw. 544/31 ( $-31 / 32)$, $1 \times$ D Craw. 544/33 (-31/32), $1 \times$ D Craw. 544/34 (-31/32), $1 \times$ D Craw. 544/35 (-31/32), $11 \times$ Craw. 544 unbestimmbar $(-31 / 32), 1 \times$ Augustus D RIC 271 Roma (-29/27), $1 \times$ Augustus D RIC 37 Hispania (-19/18), $1 \times$ Augustus D RIC 99 oder 100 Hispania (-18), $1 \times$ Augustus D RIC 187 Lugdunum (-11/10), $1 \times$ Augustus D RIC 212 Lugdunum (-7/6), 6× Tiberius D RIC 26/28/30 Rom (36/37), $1 \times$ Nero D RIC 53 Rom (64/68).

Literatur: PROHÁSZKA 2013.

Jászdózsa (Kom. Szolnok, Ungarn) (Abb 1.3)

Die Goldmünze kam in Jászdózsa zum Vorschein und wurde vom Nationalmuseum gekauft.

Münze: $1 \times$ Tiberius Au Rom RIC 25 (14-37).

Literatur: Ungarisches Nationalmuseum (Budapest) Münzkabinett 44/1898.

Jászfényszaru (Kom. Szolnok, Ungarn) (Abb 1.4)

Im Herbst 1892 wurde eine römische Goldmünze des Claudius in der Gemarkung des Ortes gefunden. Aus dem Dorf ist noch ein As des Claudius bekannt.

Münze: $1 \times$ Claudius Au RIC 36 Rom (46/47), $1 \times$ Claudius As.

Literatur: VADAY 1975, 6, Nr. 15-16.

Jászjákóhalom (Kom. Szolnok, Ungarn) (Abb 1.IV)

Im Herbst 1897 kamen vier Münzen beim Pflügen zum Vorschein. Sie gelanten durch den Notar des Dorfes in die Sammlung von Viktor Hild. Nur eine Münze wurde von Hild beschrieben.

Münze: $1 \times$ D Craw. 281/1 Rom (-119), $3 \times$ D unbekannt.

Literatur: VADAY 1975, 5, Nr. 10.

Jászkisér (Kom. Szolnok, Ungarn) (Abb 1.5)

Die Münze mit Fundort Jászkisér wurde ins Ungarische Nationalmuseum geschickt, um ihren Wert zu erfragen.

Münze: $1 \times$ Nero Au Rom RIC 25 (60/61) oder 31 (61/62) oder 36 (62/63).

Literatur: Ungarisches Nationalmuseum (Budapest) Archiv, Akten des Münz- und Antikenkabinetts 666/1906.

Szolnok (Kom. Szolnok, Ungarn) (Abb 1.6)

Eine republikanische Silbermünze wurde mit der Fundortangabe Szolnok ins Ungarische Nationalmuseum geschickt.

Münze: $1 \times$ D Craw. 44/1 Rom (-211).

Literatur: Ungarisches Nationalmuseum (Budapest) Münzkabinett 340A/1913. 
Chitescu 1981

CRAW

FMRU 1

FMRU 2

FMRU 3

FÜLÖP 1976

GABLER 1975

HLINKA et al. 1978

HuSZÁR 1942

JóNÁS 1926

KERÉNYI 1956

KoLNIKOVÁ-HUNKA 1994

KÖHEGYI 1972

KÖHEGYI 1984

KÖHEGYI 1999

LÁNYI 1979

MócsY 1954

MóCSY 1962

ONDROUCH 1962

ONDROUCH 1964

PeKÁRY 1956

PIETA 2010

PROHÁSZKa 2013

RIC I.

TORBÁGYI 1984

VADAY 1970

VADAY 1975

VADAY 1989
= M. Chitescu: Numismatic Aspects of the History of the Dacian State. The Roman republican coinage in Dacia and Geto-Dacian coins of Roman type. BAR IntSer 112. Oxford 1981.

$=$ M. H. CRAWFORD: Roman Republican Coinage. I. Cambridge 1983.

$=$ J. FitZ (Hrsg.): Die Fundmünzen der römischen Zeit in Ungarn. 1.: Komitat Fejér. Bonn-Budapest 1990 .

= V. LÁNYI (Hrsg.): Die Fundmünzen der römischen Zeit in Ungarn. 2.: Komitat Györ-Moson-Sopron. Bonn-Budapest 1993.

= F. REDÓ (Hrsg.): Die Fundmünzen der römischen Zeit in Ungarn. 3.: Komitat Komárom-Esztergom. Berlin-Budapest 1999.

= Gy. FÜLÖP: Újabb tanulmány a római érmek szarmatakori forgalmáról a mai magyar Alföldön (A new paper on the circulation of Roman coins during Sarmatian times on the contemporary Great Hungarian Plain). ArchÉrt 103 (1976) 253-262.

= D. GABLER: Zur Frage der Handelsbeziehungen zwischen den Römern und den „Barbaren“ im Gebiet östlich von Pannonien. In: Römer und Germanen in Mitteleuropa. Hrsg.: H. Grünert. Berlin 1975, 87-121.

= J. HLINKA-E. KolnikovÁ-L. Krasková-J. NovÁK: Nálezy mincí na Slovensku [Ancient Coinage in Slovakia] III. Bratislava 1978.

= L. HusZÁR: Éremleletek (Münzfunde). NK 41 (1942) 66-68.

= E. JóNÁs: A tiszanagyrévi római éremlelet (Der römische Münzhort von Tiszanagyrév). NK 23-24 (1924-1925) [1926] 38-40.

= A. KERÉNYI: Magyarországi szarmata pénzek (Sarmatische Münzen aus Ungarn). NK 54-55 (19551956) [1956] 14-20.

= É. Kolniková-J. HunKa (Hrsg.): Nálezy mincí na Slovensku [Die Fundmünzen in der Slowakei] IV. Nitra 1994.

= M. KöHEGYI: Római pénzforgalom és kereskedelem az Intercisa-Csongrád közötti útvonalon (Römischer Münzumlauf und Handel auf der Strecke zwischen Intercisa und Csongrád). Cumania 1 (1972) 103-114.

= M. KÖHEGYI: Kora szarmata aranyleletes női sírok az Alföldön (Frühsarmatische Frauengräber mit Goldfunden in der Großen Ungarischen Tiefebene). DMÉ 63 (1982) [1984] 267-356.

= M. KŐHEGYI: Újabb adatok a római pénzforgalom és kereskedelem Lugio-Szeged közötti szakaszához (Neuere Angaben zum Münzverkehr und Handel des Abschnitts zwischen Lugio und Szeged). In: Emlékkönyv Bíró-Sey Katalin és Gedai István 65. születésnapjára - Festschrift für Katalin Bíró-Sey und István Gedai zum 65. Geburtstag. Hrsg.: K. Bertók, M. Torbágyi. Budapest 1999, 191-208.

= V. LÁNYI: A kora császárkori pénzforgalom alakulása Pannoniában (Die Entwicklung des frühkaiserzeitlichen Münzverkehrs in Pannonien). ArchÉrt 106 (1979) 195-205.

= A. MócsY: K voproszi o periodizacii ranneszarmatszkoj epochi (Zur Periodisierung der frühen Sarmatenzeit in Ungarn). ActaArchHung 4 (1954) 115-128.

= A. Mócsy: A római pénzforgalom a római uralom előtti Pannoniában (Der römische Geldumlauf in Pannonien vor der römischen Machtergreifung). NK 61 (1962) 15-18.

= V. ONDROuCH: Mince Rímjskej republiky na Slovensku (Funde von Münzen der römischen Republik in der Slowakei). ŠtZ 9 (1962) 169-185.

= V. ONDROUCH: Nálezy keltských, antických a byzantských mincí na Slovesnku [Les monnaies celtiques, antiques et byzantiniques découvertes en Slovaquie]. Bratislava 1964.

$=$ T. PEKÁRY: Kunfehértói éremlelet a III. századból (Der Münzhort von Kunfehértó aus dem 3. Jahrhundert). NK 54-55 (1955-1956) [1956] 50-52.

= K. PIETA: Die keltische Besiedlung der Slowakei. Nitra 2010.

= P. ProhÁszKa: A jászdózsai római dénárlelet a Kr. u. I. század közepéről (Der römische Denarfund von Jászdózsa aus der Mitte des 1. Jahrhunderts n. Chr.). Tisicum 22 (2013) 79-90.

= C. H. V. SutherLand: The Roman Imperial Coinage. 1.: From 31 B.C. to A.D. 69. London 1984 (Rev. ed.)

= M. TORBÁGYI: Die Münzprägung der Eravisker. ActaArchHung 36 (1984) 161-196.

= A. VADAY: Szolnok megye rómaikori pénzforgalma (Der römerzeitliche Geldumlauf des Komitats Szolnok). Jászkunság 16/3 (1970) 130-138.

= A. VADAY: Szolnok megyei éremtani adatok - Hild Viktor jegyzeteiből (Numismatische Angaben für Komitat Szolnok aus den Notizen von Viktor Hild). Szolnok megyei múzeumi adattár 27. Szolnok 1975.

$=$ A. VADAY: Die sarmatischen Denkmäler des Komitats Szolnok. Ein Beitrag zur Archäologie und Geschichte des sarmatischen Barbaricums. Antaeus 17-18. Budapest 1989. 
VADAY 1998

VADAY 2005a

VADAY 2005b

WINKLER 1967
= A. VADAY: Kereskedelem és gazdasági kapcsolatok a szarmaták és a rómaiak között (Handel und wirtschaftliche Kontakte zwischen den Sarmaten und Römern). In: Jazigok, roxolánok, alánok (Szarmaták az Alföldön). Hrsg.: B. Havassy. Gyulai katalógusok 6. Gyula 1998, 117-143.

= A. VADAY: Corpus der römischen Funde im europäischen Barbaricum. 1.: Komitat Szolnok. Budapest 2005.

= A. VADAY: The Jászság in the Iron Age, the Roman Period and the Migration Period. In: Environmental Archaeology in North-Eastern Hungary. Eds: E. Gál, I. Juhász, P. Sümegi. VAH 19. Budapest 2005, 359-363.

= J. WINKLER: Schatzfunde römischer Silbermünzen in Dakien bis zum Beginn der Dakerkriege. JNG 17 (1967) 133-156. 